\title{
Economic texts: the cognitive aspects of translation
}

\author{
Evgenia Krasnova* \\ Don State Technical University, 344002, Rostov-on-Don, Russia
}

\begin{abstract}
The paper explores economic texts from the translation process point of view. The study was carried out on the textual level, within the terminology in particular. The author holds the view that the formation of economic terminology is based on cognitive aspects of the language. In accordance with this view economic terms were evaluated in respect to the strategies of their borrowing into the language. Also classification of English economic terms is given. The results show that the ways of translating economic terminology are included both in the terminological base of the economic field of knowledge, and belong to other terminologies, and even represent non-terminological systems. The author conclude that complex untranslated unambiguous terms occur with the same frequency as simple ones. Thus, adequate translation of economic texts from English into Russian requires knowledge not only of the terminological systems but also of the cognitive apparatus of economic science.
\end{abstract}

\section{Introduction}

The financial sphere is one of the most essential components in the life of the society, in other words, everything that concerns the creation, distribution, exchange and use of the amenities created by human labor. It is not for nothing that today economic translation is one of the most popular types of translation. The reasons for its popularity were the expansion of business and the formation of the state economy. Cooperation in the global market has brought therise in the flow of documents. The level of interest in the language and its knowledge increases every day. The process of translating economic texts is impossible to imagine without knowledge of the terminology base of this field.

The purpose of the research is to study cognitive aspect of economic texts ' and terms ' translation. To achieve the purpose the following steps should be done:

To analyze borrowings and assimilation of foreign lexis;

To study features of English economic terminolexis;

To identify basic ways of translation terms in economic sphere.

In modern linguistics, the cognitive approach allows us to overcome such language problems as identifying the organization of term systems. And the impact of the language on international business have been much discussed [1-5].

*Correspondingauthor krasnova07@inbox.ru 


\section{Materials and methods}

The material for the study has been obtained from economic publicistic texts of English and American origin. In addition, general classifications of terms were used to study the practical material. After this stage was completed, we studied the terms within the formation and translation processes, taking into account general laws of formation of the terms and unambiguous and polysemantic terms that have the property of untranslation.

To analyze and classify manually extracted economic terms, a descriptive and comparative methods, text and contextual-analysis methods have been applied.

\section{Results}

In today's world, the topic of research of special texts not only does not lose its relevance, but on the contrary continues to develop rapidly. The influence of commodity-money relations leads to the fact that the demand for the translation of economic texts increases. These include the translation of economic documentation, namely invoices, bank statements, as well as economic statistics, audit reports, scientific publications, and more.

The style of modern English economic literature is based on the norms of the English written language with certain specific characteristics, namely:

1. Vocabulary. A great number of terms and words of non-Anglo-Saxon origin are used. The words are carefully selected to convey the thought as accurately as possible. Service (functional) words (prepositions and conjunctions) and words that provide logical connections between individual elements of utterances (adverbs) have a large share.

2. Grammar. Only grammatical norms that are firmly established in written speech are used. Passive, impersonal, and vaguely personal constructions are widespread. For the most part, compound and compound sentences are used, in which nouns, adjectives, and nonpersonal forms of the verb predominate. Logical selection is often achieved by deviating from the solid word order (inversion).

3. The method of presentation of the material. The main task of economic literature is to bring certain information to the readers very clearly and accurately. This is achieved by a logically sound presentation of the actual material, without the use of appellative lexis, expressions and grammatical constructions.

Dictionaries should make a substantial contribution in the translation of economic texts. However, it is known that the main drawback of dictionaries is that they go beyond the progress of the economy. In addition, published dictionaries are rarely exclusively specialized. Due to the complex evolution of the English language, synonymy is widely developed, including lexical: the same concept can be expressed in different ways, mainly of Anglo-Saxon or Latin (French) origin.

Teaching interpreters special translation in the field of professional communication is characterized by the necessity to develop students' competence to work with texts of various functional styles and genres, and the competence to professionally translate special texts is the main qualification requirement.

Therefore, one of the elements of translation competence is text-forming competence, which is understood as knowledge of the relationship between the rules for generating texts in the native and foreign languages, the principles of translating texts related to a particular sublanguage of the specialty, possession of the skills to build texts adequate to the original of a certain style, genre and type.

The essence of economic texts is, first of all, in their satiation with terms that express the basic concepts of economics and which contain the main information on the branch. Ignorance of the terminological vocabulary creates the main real difficulties in translation. That is why, the assimilation of special terminology to the extent necessary and sufficient 
for the confident ability to translate professionally significant texts from a foreign language into the native language is one of the objects of purposeful action of the translator.

The object of research in translation studies, according to philologists, is a bilingual act of communication, which at the same time is a bilingual communication, starting from the creation of the original text in English and completing the process of acceptance by the recipient of the translation text. At the same time, the features of bilingual communication are studied: the stages of the translation process; the text units used by the translator; the cooperation of linguistic and extralinguistic factors. Every language within the translation process has a number of opportunities to replace the semantics of words and phrases in these consituative conditions of expression for the needs of monolingual communication. Note that in the course of translation, the translator chooses the necessary meanings of language units that have similarly managed to find their niche in a different space of the metalanguage. This phenomenon can also be observed in the object language, which is analyzed to select the most appropriate values for the purpose of translation. The translation process compares languages and their elements, equates, replaces each other in communication [6, p. 75]. Nevertheless, the above-mentioned experiment has a creative nature, which is why the main component of cross-language communication is the translator's thinking, thanks to which there is a transition from one language system to another. Such psychological phenomena as probabilistic forecasting, intuition, paradigmatic variability of the meanings of formal grammatical constructions, etc. are also taken into account in translation activities.

Kinchina E. V. suggests that the study of the term within the translation process as a unit of cognitive-functional activity implies the identification of cogniotypes. This approach assumes that the term is considered as a cogniotype, i.e. a unit of a language of a limited scope of use, denoting a specific concept and having a specific area of knowledge of the speaker. It should be noted that the ability to adequately perceive the cogniotype allows the recipient to choose the most accurate equivalent of the term when translating. Moreover, the phenomenon of unambiguity, polysemy, synonymy, antonymy, and other things in term systems can be taken as variants of the cogniotype, since they fill in the socalled cognitive gaps, i.e. gaps in the text that are formed due to the recipient's insufficient knowledge of background knowledge, context, or situation. [6, p.17].

It should be mentioned that the composition of economic terminology is not homogeneous due to a rather extensive layer of borrowings from related sciences. Like other terminological systems, economic terminology is formed according to general laws, where there are gradualness and jumps, qualitative growth and changes. The formation of economic terminology is the process of the existence of a system where missing elements are borrowed from another language, and already known terms acquire a new meaning. All new terms must pass the so-called natural selection for compliance with the language and general trends in the development of this system.

Borrowing and translating terms are two aspects of cross-language interaction. Studies on the nature of lexical pragmatics have enabled philologists to conclude that the main stage of the algorithm for borrowing each lexical innovation into a language is its adoption in speech, the pragmatic assignment to the lexical unit of a number of similar social examples of its use and non-use.

The borrowing algorithm, as well as the translation process, is caused by the cognitive aspect, in particular, the formation of cogniotypes. In this paper, we refer to the terms as cogniotypes. The structure of cognitive factors includes the ways of thinking peculiar to communicants. For example, we can assign the jargon of a professional field to a metalanguage of a certain sphere of use, which implies both as an individual and a mass cognitive system inherent in a separate group of specialists. So, the words-the terms audit, off-shore, hedging, consignee, futures transactions are clear to specialists-economists and 
completely unfamiliar to a wide range of people. These examples show the high importance of the translator or dictionary as a connecting component of communicants, through which the cognitive gaps in the TL are filled.

Borrowing is explained by the complex influence of external and internal factors on the language system. Intrasystem, intralinguistic prerequisites, conditions and reasons for borrowing essentially correspond to the reasons, conditions and prerequisites for absolutely all innovations in the vocabulary [7, p.95]. Today, borrowing implies an element of a foreign language (word, morpheme, syntactic construction, etc.), transferred from one language to another [8]. Borrowing, usually, is an appeal to the lexical component of other languages to name new concepts in the TL, the subsequent differentiation of existing ones and the definition of previously unknown objects.

The main characteristic of the borrowing process is considered to be the complete transition of the word from the system of OL to TL. So, 7 signs of the transition of a borrowed word are:

1) grammatical development;

2) phonetic development;

3) participation of the borrowed lexeme in word-forming processes in the recipient language;

4) semantic development;

5) correlation of a foreign language word with certain grammatical classes and categories in the recipient language;

6) grapheme-phonetic transmission of a foreign language word by means of the recipient language;

7) regular use in speech $[9$, p. 43].

Terminology bases are of an interlinguistic nature. That is why we should study the bases from the universal interethnic contact point of view. At the same time, the dominant role of the English language in the modern world is of particular importance, thanks to which the composition of scientific and technical terminology is replenished. We consider it necessary to consider the borrowing and internationalization of language units within the corpus of terms, as well as the impact of these phenomena on the translation process of terminolexics. Given the peculiarities of the term, we can assume that the term lexicon is not an obstacle to understanding and translation. This is due to the presence in any term system of a certain number of internationalisms, the semantic content of which is the same in different languages. However, the number of internationalisms in the vocabulary of different terminosystems varies, which is why they are lost in the total number of national, as well as borrowed terms.

According to the sociolinguistic feature, there are three types of the latest borrowed terms. The most common are considered:

a) borrowing due to cultural influence. Another type of borrowing combines;

b) terms that are included in the language for the nomination of realities already known to society, but do not have their own designation;

c) the actual language influence. This type combines borrowed terms that have a meaning suitable for denoting a new, specific phenomenon of life that does not exist in the places where the TL operates. Borrowings of this type are not numerous, but the trend is quite clear if you touch on the material from various thematic groups.

The question of translating economic terminology together with the question of borrowing new vocabulary should be studied through cognitive linguistics[10]. This statement makes sense, since the translation process and the borrowing process are aspects of cross-language interaction. In this aspect, the terms act as cogniotypes, and their lexical variants, synonyms, homonyms, and so on, respectively, as variants of the cogniotype. 
During the English into Russian translation process, the translator searches for an equivalent term in the Russian language for the English economic term. Difficulties arise just at this stage of the work, which it is important to overcome in order to achieve an adequate translation of the text.

The translator, who operates with narrowly focused scientific knowledge, compares the pictures of the world of the addressee and the recipient, superimposing them on a vast socio-cultural context - this process helps to fill in the cognitive gaps in the TL. Professional translation is a knowledge of both terminological systems of translating languages and the cognitive apparatus of the economy. We are faced with the fact that most of the terminology of the English language has many ways of translation, or variants of the cogniotype. Usually, these are simple terms that are not phrases. Here are a number of terms:

\section{Account:}

1) account entry; account;

2) the period when exchange transactions are concluded with the closing of the position on the settlement day;

3) report (financial); amer. broker's record of transactions made on behalf of the client;

4) financial statements;

5) business books;

6) bookkeeper`s accounts [11, p. 18].

Bill:

1) an invoice;

2) a document (certificate, certificate, etc.);

3) a list;

4) a bill of exchange, a draft;

5) a remanent;

6) a banknote, a treasury note [11, p. 29].

Deposit:

1) fee;

2) field;

3) earnest, payment;

4) bank deposit; investment [11, p. 63].

Credit:

1) loan;

2) letter of credit;

3) bookkeeper`s credit, right side of the account;

4) trust $[11$, p. 55].

After analyzing several economic texts, we found that the ways of translating economic terminolexics are included both in the terminological base of the economic field of knowledge, and belong to other terminologies, and even represent non-terminological systems.

Therefore, the terms that we have worked with can be divided into single-translated and multi-translated. Untranslated terms are the terms that have one translation variant, or one equivalent. Terms that have two or more equivalents are often referred to as differently translated terms. Speaking about the ordering of economic terminolexics, we should not forget about their semantic structure. Therefore, an economic term can have several meanings, both in single-translation and in multi-translation. This fact makes it possible to classify terms by the number of values into single-valued and multi-valued ones. Terms that have a simple semantic structure, or, in other words, have only one meaning, are called unambiguous. Polysemantic terms, in turn, have a complex semantic structure and, accordingly, several meanings. 
The analysis showed that most of the terms that have a single translation method are terms that do not have a complex semantics structure. Unambiguous terms meet all the terminological requirements, the main of which is the correlation to the subject, which is observed in all unambiguous terms. The scientific definition of an economic phenomenon is a fundamental feature of single - translated unambiguous terms. This definition has to be used quite often, which is why there is a need to consolidate this term in the form of a complex word or term-phrase. It follows that a single-translated unambiguous term is a model of a scientific term. These forms are usually formed over a long period of time. This process is the result of a thorough study of the money, credit, stock markets and other sectors of the economy.

The corpus of untranslated unambiguous terms is mainly presented in the form of simple and complex phrases. We can say that they are a concentrated form of a scientific concept.For example, a term such as "leasing company".

We came to the conclusion that unambiguous and untranslated terms that are part of the terminology of the economic field of knowledge meet all the criteria for terms in general: this is unambiguity, the presence of semantic boundaries, the absence of emotional coloring.

a) Characterization of the structure of terms

The characteristic of single-translation is determined not only by the semantic structure [12]. There are many factors that determine the unambiguity and untranslation of the term. One of these reasons is the lexical and morphological structure, which, depending on the composition of the term, can be simple and complex.

It is considered that complex terms better correspond to the attraction of scientific terminology to logical certainty, and also better meet the requirement of accuracy of the term, since they allow you to more accurately distinguish between different concepts and give more opportunities to overcome ambiguity in terminology. Among the untranslated unambiguous terms, there are very few simple (one-part terms in their structure). Often these terms are part of the international vocabulary. The equivalent of such terms is internationalism with a graphic and sound similarity in the TL:

Nostro/ IT. nostroconto-our account. Bank account in a correspondent bank [13, p. 160] The Bank's correspondent network includes more than 60 Nostro accounts in about 40 banks in 17 currencies).

Loro/ um. loroconto - their account. An account for the correspondent bank [13, p. 121] (According to the latest data, special attention is being paid to loro and nostro money remittance).

The analysis of the studied terms allowed us to conclude that complex untranslated unambiguous terms occur with the same frequency as simple ones. Complex terms have the same sound and visual design and are a reflection of similar concepts in languages, which thus unites them with simple terms.

Analyzing economic texts, we came to the conclusion that in addition to similarities, single-translated unambiguous simple and complex terms have differences. The international language fund does not include all terms that have a complex structure. In addition, complex terms can indicate the features of economic phenomena. This property of complex terms is called motivation. An example is the term"eurodollars" - Eurodollarsmonetary units used in European banks for credit operations [9, p. 74].

In addition, the main number of untranslated unambiguous terms are word combinations. Once again, we recall that, like words, phrases can be simple and complex, and it should be taken into account that the number of the first is much larger. The words included in the phrases can be both terms and non-terminological units. Without forming a phrase, individual words can have several meanings, these words can be multi-valued, but 
in a certain combination with another word, they represent a single-translated unambiguous term.

It should be mentioned that the main part of the studied terms is characterized by monosemy, but the above-mentioned special vocabulary is also characterized by polysemy. In the course of working with polysemantic terms, we take as a basis the paradigmatic correlation of meanings based on the semantics of the word. From this point of view, the variants of terms translation act as a cogniotype. Thus, the gaps in the TL are filled in.

A single-translated unambiguous term is an ever-changing and evolving unit of language. In different periods of time, it can be single-translated, then due to changes in the field of economics and language, there is a high probability of the appearance of a doublet of a single meaning, as a result of which this term passes into the category of multitranslatable. These changes can be repeated many times. So, a term can be single-translated, then multi-translated, and then single-translated again.

Therefore, single-translated unambiguous terms can be:

1. Simple:

a) formed on the basis of Latin, French, Italian, German and other languages. A small part of them were borrowed before they entered the English language: nostro - nostro (it), loro-lora (it), deficit-deficit (lat);

b) formed on the basis of the vocabulary of the English language: dollarization, devaluation;

2. Complex terms:

a) complex words: know-how;

б) simple phrases: statutory documents;

c) complex phrases: interest-bearing deposit.

In the process of changing the language, changes are also observed in terms. Depending on the time and events, the term can move from one category to another, which is due to the need for fast and high-quality translation of economic documentation.

Based on the specifics of the term, namely its unambiguity, correlation with a certain area of knowledge, and so on, it makes sense to say that when translating terms, there are no difficulties in understanding. This phenomenon also depends on the number of words that are semantically common to all languages, or as they are called "internationalisms". However, the number of such words varies in all languages, that is why they are lost among the original and borrowed terms. We believe that the borrowing process should be studied from the point of view of their influence on the translation of terms. Within the process of translating the terms, semantics should be of special attention. There are many semantically inappropriate words. Borrowed terms do not always represent the exact equivalent of a concept, which is not true of the original meaning in the OL. In these cases, we can talk about a complete or partial mismatch of the value. Scientists say that the study of internationalisms includes the search for similarities in terms of the content and expression of languages, as well as the establishment of general trends in their development [14].

It is known that a significant phenomenon of the similarity of the plan of content and expression of various types and forms of languages is internationality.

We know that the term passes into the category of internationalisms by introducing several languages into the terminological corpus. No less important is the international vocabulary in the translation process.

When identifying the meaning of international vocabulary, one of the main conditions is equivalence and clarity in the context in cases of correlation of the OL and the TL. It is no secret that when languages are correlated and their typological distance is increased, the level of internationalization increases. In this study, we take as a basis the comparison of the terminological base of the Russian and English languages. When studying the genetic 
characteristics of the term system, we found that the main sources of borrowing were: Latin, English, French, Greek, German, Italian, Dutch.

Both unambiguous and polysemantic terms have the property of untranslation, in the case of a complex semantic structure. Other meanings may refer to the economic composition of the terminology, non-terminological, and even be representatives of common vocabulary. But in all cases, the graphic and sound structure of these different values will be identical.

An economic term that has one translation from English to Russian, but several meanings, is 'crossing', which has different meanings depending on the field of economics.Crossing 1) bank. check crossing (drawing two parallel lines diagonally, according to which the bank pays to another bank on the order of the owner of the crosscheck or to its client, the owner of the current account, by crediting the amount of the check to their accounts, without resorting to cash payment. It is used to make it difficult for other persons to use the check in the event of its loss or theft); 2) exchanges. cross-over (simultaneous purchase and sale through one broker of the same block of shares) $[15,16]$.

In the course of working in the field of economics, the translator, in order not to get into difficult situations associated with the translation of such terms, should read them in advance. It is also worth saying that in the case when the meaning is part of another terminology, the frequency of use of non-terminological vocabulary increases here. For example, this is a common phenomenon in the field of determining the investment qualities of securities and profitability: determining the interest rate, classifying rents and their individual types, the impact of inflation on the value and profitability of securities, determining the value of leasing, factoring, currency and other operations. Examples of the use of non-terminological meanings of economic untranslated polysemantic terms in economic texts were not found in the course of the study.

If we talk about the degree of borrowing of untranslated polysemantic terms from other languages, it can be noted that in this body of terms there are both loanwords and English words:

Deflation - (late Latin deflatio) 1) geological grinding and grinding of rocks with mineral particles carried by the wind; 2) econ. withdrawal from circulation of part of the money issued during the period of inflation.

Studying the structure of terms from their morphology point of view, we came to the conclusion that simple terms in the number of untranslated ones with different meanings are more common than complex ones.

We can say that there are much more single-valued terms than there are multi-valued terms. Polysemantic terms are in most cases units of the English vocabulary, which cannot be said about unambiguous ones. The meanings of polysemantic terms can be part of both the terminological base of the economic field of knowledge, and any other, or even be a common vocabulary.

The main difficulty in the activity of the translator when working with economic texts is the translation of different translated terms. Such terms can have several variants of meaning translation. We have already found out that untranslated terms can be both unambiguous and polysemantic terms. The uniqueness in such cases was characterized by the unity of the graphic and sound form of the unit in both languages. With regard to the different-translated terminolexics, it can also refer to both unambiguous and polysemantic. The difference in translation in the case of unambiguity is the result of phenomena occurring in the Russian language, and the difference in translation in the case of polysemy is the result of processes occurring in the English language.

If we compare the semantic structure of untranslated unambiguous terms and untranslated unambiguous terms, we will find absolute similarity due to the translation variants (hereinafter referred to as doublets) are the same concepts: 
futures-futures transactions, transactions for the term;

consignee - consignee; consignee; addressee of the cargo (The contract showing the consignee of these flights. Contract with the indication of the consignee).

One of the grounds for the classification of terminology that is particularly relevant to the problems of translation is the criterion of unambiguity and polysemy, single-translation and multi-translation.

So, in the study of economic terms - differently translated and untranslated with unambiguity and polysemy, for which we take the connection of the semantic structure with the conceptual one as the basis. Multitranslation with unambiguity is the presence of two or more doublets of an economic term with a single meaning. Sources of doublet can be: tracing (the formation of a word or expression by literally translating a foreign word or expression), borrowing (the use of foreign words), metaphorization (figurative convergence of words based on their figurative meaning).

When translating multi-valued multi-translated terms, the translator is also not free to choose the translation option. However, in this case, the translation process is even more complicated by the fact that the term has several meanings within one terminological system (in our case, economic), several terminological systems, including economic, and may also have meanings belonging to non-terminological vocabulary.

In the course of the study, there were examples of the second method of forming doublets by borrowing. So, the term endorser (the person who puts a transfer inscription on the back of the bill) in the Russian language "endorser" is used. Doublets are also formed by metaphorizing, or figurative convergence of words based on their figurative meaning: revolving credit-automatically renewable credit. Another way to form a doublet can be considered morphologic language changes, hence their name "morphological doublets": hedge exchanges - hedging; hedge; there are examples when the doublet is a word and a phrase: bill with recourse - recambio; reverse bill.

If there is a doublet, the sources of polysemy are: homonymy - similarity of sound with different meanings; polysemy - polysemy; conversion - change in grammatical characteristics when forming a word.

In the course of consideration of untranslated polysemantic units of the economic term system, we saw that polysemicity is heterogeneous from the point of view that a term can have meanings that belong not only to economic terminology, but also to some other terminology, or be a representative of non-terminological vocabulary. Taking into account the fact that there are much more multi-valued terms of different translations than there are multi-valued terms of one translation, this issue becomes particularly acute and causes the division of multi-valued economic terms of different translations into two groups: a) mixed economic terms; b) pure economic terms.

Mixed economic terms are terms whose meanings belong either to an economic or some other term system, or to a non-terminological vocabulary. Pure economic terms are terms whose meanings are within the limits of economic terminology only. Such a classification, in our opinion, could serve for practical purposes: it would be much easier for a translator to work if all the meanings of multi-translated polysemantic terms were embedded in a computer data bank. In addition, the principle of classification of multi-translated polysemantic terms that cause the most difficult moments of translation can be used in the compilation of economic dictionaries.

The first group of terms represents the most numerous and difficult to translate terms. Since mixed economic terms differ by belonging to a particular term system, or perhaps even non-terminological vocabulary, they, in turn, are divided into the following groups:

1. Economic terms which meanings are included in the economic term system or any other terminology. For example: warrant 1) econ. guarantee; 2) econ. powers of attorney; 3) econ. certificate, receipt; 4) econ. coupon (bonds, shares); 5) econ. patent (for labor 
activity); 6) econ. the right to buy or sell securities for a certain period; 7) a lawyer; court order; lien 1) econ. pledge law; 2) jurid. the right to withhold property before tax; deposit 1) econ. contribution; 2) econ. bank deposit; 3) econ. pledge; 4) chemical. sediment; 5) gorn. deposit.

2. The economic meanings which are found in the economic terminological system and non-terminological vocabulary: par 1) econ. par value, par value of securities, parity; 2) nonterm. equality; list 1) econ. course bulletin; 2) nonterm. list, register, option 1) econ. premium transaction; 2) nonterm. the right to choose or replace.

Terms related to economic terminology, non-economic and non-terminological vocabulary: spot 1) econ. cash goods; 2) nonterm., place; 3) econ. goods for cash transactions; 4) recl. commercial; principal 1) econ. commitee; principal; 4) econ. capital, principal amount; 2) nonterm. principal, head, chief; 3) image, university rector; college director; grant 1) nonterm. gift; 2) jurid. donation; 3) econ. one-time payment; 4) econ. subsidy; 5) nonterm. scholarship

\section{Discussion}

Depending on what other areas of use the terms of the economic field of knowledge may belong to, the meaning of the terminological units changes. For example, the rapid development of legislation is the reason for the emergence of legal terms in economic discourse. To translate these economic terms, you will need to determine its meaning, this can be done by referring to the context. Based on the above, it can be noted that the meaning of the term has a semantic connection with other words.

In the course of the analysis of multi-translated polysemantic terms, we came to the conclusion that the translation of these lexical units brings extra translation difficulty.

In conducting the research, we used the following features of the cognitive direction: the close connection of the semantic structure with the conceptual one, the informational structure of meaning in natural language, plausibility and verifiability in conducting semantic analysis. This explains the presence of a large number of values, firstly, and the heterogeneity of these values, secondly. The different meanings of such economic terms may belong to an economic term system, to some other term system, or to a nonterminological vocabulary. From this point of view, multi-translated polysemantic economic terms are divided into two groups, the first of which, in turn, represents three subgroups. In our opinion, this classification will help the translator not to get confused in a large number of meanings.

The analysis of the material under study showed that most of these terms belong to the English vocabulary, although there are words borrowed from other languages. The vast majority are simple words, among which it is extremely rare to find complex phrases.

An adequate translation of economic texts from English into Russian requires knowledge not only of the terminological systems of the corresponding languages, but also of the cognitive apparatus of economic science.

\section{Conclusion}

Adequate use of communicative competence occurs through the interaction of the pragmatics of words and utterances with different context conditions. Communicative value is a pragmatic prerequisite for borrowing a word. This factor is of particular importance in the study of borrowings within the framework of the language system.

The analysis of the material under study gave us the right to assert that both Russian economic terminology and English have gone from a term (their totality) to a system. 
Economic terminology is a system that is characterized by multiple elements, microsystems, interconnectedness, and openness.

One of the grounds for the classification of terminology that is particularly relevant to the problems of translation is the criterion of unambiguity and polysemy, single-translation and multi-translation.

So, in the study of economic terms - differently translated and untranslated with unambiguity and polysemy, for which we take the connection of the semantic structure with the conceptual one as the basis. Multitranslation with unambiguity is the presence of two or more doublets of an economic term with a single meaning. Sources of doublet can be: tracing (the formation of a word or expression by literally translating a foreign word or expression), borrowing (the use of foreign words), metaphorization (figurative convergence of words based on their figurative meaning).

When translating multi-valued multi-translated terms, the translator is also not free to choose the translation option. However, in this case, the translation process is even more complicated by the fact that the term has several meanings within one terminological system (in our case, economic), several terminological systems, including economic, and may also have meanings belonging to non-terminological vocabulary.

\section{References}

1. W. Travis Selmier, Chang Hoon Oh, Business Horizons 55, 189-200 (2012) doi.org/10.1016/j.bushor.2011.11.006

2. Csilla Weninger, Katy Hoi-Yi Kan, English for Specific Purposes 32, 59-71, (2013) doi.org/10.1016/j.esp.2012.09.002.

3. Anne-Wil Harzing, Kathrin Köster, Ulrike Magner, Journal of World Business 46, (2011) doi.org/10.1016/j.jwb.2010.07.005.

4. S.E. Marchenko, A.K. Boiko, E.E. Laskina, O.B. Moisova, SGEM International Multidisciplinary Scientific Conference on Social sciences and Arts 5(3.1), 509-516 (2018)doi: 10.5593/Sgemsocial2018/3.1

5. Maria Efimova, Evgeniya Krasnova, Svetlana Marchenko, Elena Velichko, Anna Boiko, SGEM 2016, BK 1: Psychology and Psychiatry, Sociology and Healthcare, Education Conference Proceedings III, 1035-1040 (2016) doi: 10.5593/SGEMSOCIAL2016/B13/S03.135

6. E. V. Kinchina, Cognitive aspects of the translation of economic terms, PhDThesis, (2010)

7. U. Weinreich, Language contacts (Monograph, 2011)

8. Gisle Andersen, Cristiano Furiassi, Biljana Mišićslić, Journal of Pragmatics 113, 71-76 doi.org/10.1016/j.pragma.2017.03.010

9. L. P. Krysin, Russian language at the end of the XX century 6, 38-43 (2000)

10. Liliya A. Nefedova, Irina N. Remkhe, Procedia - Social and Behavioral Sciences, 154, 237-244 (2014). doi.org/10.1016/j.sbspro.2014.10.143

11. E.N. Shagalova, Dictionary of the latest foreign words (2020)

12. Leila Mirzoyeva, Procedia - Social and BehavioralSciences 136, 169-174 (2014). doi.org/10.1016/j.sbspro.2014.05.309.

13. B.D. Hodjageldyiev, O.S. Shurupova, Illustrated Dictionary of English Loanwords in the Russian language of recent years (2020) 
14. Elizabeth Peterson, Journal of Pragmatics 113, 116-126 doi.org/10.1016/j.pragma.2017.02.012

15. D. Burger, Wealthfront Wants to Make Investing Complicated Again, Bloomberg. https://www.bloomberg.com/news/articles/2018-05-11/wealthfront-wants-to-makeinvesting-complicated-again. (date of request: 27. 04. 2021).

16. A.A. Di Paola, Mideast Energy Giant Seizes New Energy Future, Bloomberghttps://www.bloomberg.com/news/articles/2018-05-10/as-saudis-pursuearamco-ipo-abu-dhabi-hedges-to-stay-relevant. (date of request: 27. 04. 2021). 